\title{
Deformable Bowtie Antenna Realized by 4D Printing
}

\author{
Lei $W u{ }^{1}$, Jiawei Huang ${ }^{1}$, Minglong Zhai ${ }^{1}$, Bing Sun ${ }^{1}$, Hudong Chang ${ }^{1, *}$, Sen Huang ${ }^{1, *} \mathbb{C}$ and Honggang Liu ${ }^{2, *} \mathbb{C}$ \\ 1 The Key Laboratory of Microelectronic Devices \& Integrated Technology, Institute of Microelectronics, \\ Chinese Academy of Sciences, Beijing 100029, China; wulei@ime.ac.cn (L.W.); huangjiawei@ime.ac.cn (J.H.); \\ zhaiminglong@ime.ac.cn (M.Z.); sunbing@ime.ac.cn (B.S.) \\ 2 Department of Electronics, Peking University, Beijing 100871, China \\ * Correspondence: changhudong@ime.ac.cn (H.C.); huangsen@ime.ac.cn (S.H.); \\ liuhonggang@pku.edu.cn (H.L.)
}

check for updates

Citation: Wu, L.; Huang, J.; Zhai, M.; Sun, B.; Chang, H.; Huang, S.; Liu, H. Deformable Bowtie Antenna Realized by 4D Printing. Electronics 2021, 10, 1792. https://doi.org/10.3390/ electronics10151792

Academic Editor: Antonio Di Bartolomeo

Received: 19 June 2021

Accepted: 19 July 2021

Published: 26 July 2021

Publisher's Note: MDPI stays neutral with regard to jurisdictional claims in published maps and institutional affiliations.

Copyright: (C) 2021 by the authors Licensee MDPI, Basel, Switzerland. This article is an open access article distributed under the terms and conditions of the Creative Commons Attribution (CC BY) license (https:// creativecommons.org/licenses/by/ $4.0 /)$.

\begin{abstract}
D printing is utilized to fabricate of thermo-deformable bow-tie antenna to fulfill some special applications with limited space or changing antenna property. In this paper, $4 \mathrm{D}$ printing is used to manufacture nylon and carbon fiber laminated composite material. The bow-tie antenna is installed on the surface of the composite material, and the carbon fiber is energized and heated, which causes thermal deformation of the substrate to reconfigure the antenna feature. The deformation mechanism of the composite material is explained, the characteristics of the thermally deformed bow-tie antenna with power applied to carbon fiber are analyzed. The results show that the energized carbon fiber heats up, causing the structure to stretch to a flat, with a maximum gain of $2.37 \mathrm{dBi}$ and the $-10 \mathrm{~dB}$ bandwidth being $4.28-4.64 \mathrm{GHz}$ and $5.16-5.52 \mathrm{GHz}$, and the half-power beamwidth is greater than $60^{\circ}$. The structure bends at a $30^{\circ}$ angle with a maximum gain of $3.58 \mathrm{dBi}$ in the absence of external power, delivering a $-10 \mathrm{~dB}$ bandwidth range of $4.12-5.6 \mathrm{GHz}$ and a half-power beamwidth close to $45^{\circ}$. The customization of antenna radiation patterns and antenna gain can be readily tuned with power control.
\end{abstract}

Keywords: 4D printing technology; deformable antenna; flexible bowtie antenna

\section{Introduction}

3D printing has provided many conveniences for advanced manufacturing and structural design. However, structures designed by 3D printing are generally rigid and lack the potential for diverse uses. Fortunately, new technology has emerged, which is used to create structures using 3D printing while allowing controllable changes in the structures' shape, performance, or function with time and space dimensions to meet specific requirements. The integration of 3D printing and intelligent materials led to a new concept known as $4 \mathrm{D}$ printing, where $3 \mathrm{D}$ printing produces a particular shape that can change over time in response to external stimuli (e.g., heat, solvents, and light) [1-5]. With the continuous development of printing materials, polymers with $600 \%$ stretchable deformation have been developed using novel UV-assisted ink, and the printed structures have shape memory and self-recovery functions [1]. Dongping Deng reported that under uniform heating conditions, polystyrene films coated with resin materials underwent bending deformation owing to the different contraction rates of polystyrene and resin [2]. Nylon materials and polylactic acid have thermal shape-memory properties. They combine to produce a temporary shape upon heat treatment and subsequently return to the initial condition [5].

Reversible deformation of antennas also enables some new functions (e.g., remotely controlled unfolding or contraction to enhance mechanical characteristics), while the ability to reconfigure the antenna beam-shape provides a way to tune its spectral response or sense external forces. Bendable antennas are also crucial for "smart antenna" applications, i.e., beam-forming antennas. These device functions are helpful in millimeter-wave applications (e.g., automotive radar, security and surveillance systems, and high-data-rate wireless communication systems). Utilizing the characteristics of deformation, mechanically scanned 
antennas, a portion of which is designed to bend out-of-plane, offer better control than phased arrays while being more cost-effective and more efficient [5-9]. Ju Hee So designed and fabricated reconfigurable, reversibly deformable, and mechanically tunable dipole antennas, their shape and function are reconfigurable, and the resonant frequency can be mechanically tuned [6]. J.C. Langer extended and enhanced the performance of conventional planar antenna arrays by applying a magnetic field to induce plastic deformation at the antenna's edge where the antenna connects to the feed line [8]. However, adjusting the antenna length or using magnetic drive adjustment makes the structure too bulky and prone to practical problems of joint failure and has limitations in the adjustment ability.

Manufacturing highly flexible, stretchable, and reversible antennas can be applied to wearable devices. 5G communication applications are not limited to handheld devices. However, with the realization of the Internet of Everything as the ultimate vision, it is expected to provide a multi-functional and diversified network, in which device miniaturization, flexible implementation, lightweight, and cost-effectiveness are the key considering factors [9-13]. Flexible antennas have the potential to enhance the emerging field of flexible electronics, mainly due to the desire to integrate electronic products into flexible substrates (such as textiles, displays, and bandages). Liquid crystal polymer is a kind of low dielectric loss, low hygroscopicity, and chemical resistance, so it is considered to be attractive to high-frequency flexible antennas [9]. SF Jilani et al. used to switch and slotted patch antennas to achieve Ka-band antenna frequency reconstruction. The total bandwidth of the antenna in the four modes is $27.3 \mathrm{GHz}-40 \mathrm{GHz}$, and it has a peak gain of $6.2 \mathrm{dBi}$, providing frequency selection, the frequency for MIMO applications, and multi-channel transmission [12]. However, in a rapidly changing wireless environment, for reducing antenna array space on portable devices while still ensuring a highly reliable data transmission rate, it is necessary to improve the existing MIMO technology. The use of low-cost $4 \mathrm{D}$-printed deformable antennas can overcome these shortcomings. It can locally change the antenna structure through external stimuli and dynamically change its radiation characteristics according to changes in the wireless channel environment.

This paper uses low-cost $4 \mathrm{D}$-printed substrates to achieve changes in antenna performance. It has the characteristics of adjusting the pattern and frequency and can achieve the maximum gain change within a specific range. The purpose is to adjust the radiation characteristics of the antenna in real-time according to the actual needs and increase the antenna's flexibility in practical applications. We proposed the design of a deformable antenna via the combination of a $4 \mathrm{D}$-printed substrate and antenna. The antenna substrate was composed of a nylon material laminated with a conductive carbon fiber material. The paper is organized as follows: in Section 2, the structure of the 4D-printed substrate is briefly discussed, followed by a demonstration of its deformable properties; in Section 3, the design and fabrication of a bow-tie antenna; in Section 4, the bending and stretching states of the substrate are compared and analyzed, and the radiation characteristics of the antenna are discussed for achieving the control of antenna gain and directionality. Finally, the conclusions are summarized.

\section{Manufacturing of $4 \mathrm{D}$-Printed Substrate}

Nylon is a thermoplastic engineering material and is widely used in industries, including machinery manufacturing, construction, and electronics. High-performance carbon fiber has superior electrical and thermal conductivity and produces heat upon power. When continuous carbon fiber is embedded in composite material and energy is applied, the significant difference between the thermal expansion coefficients of the substrate and carbon fiber (resistivity $\rho=5 \times 10^{-3} \Omega \cdot \mathrm{cm}$ ), thermotropic deformation of the composite material can be achieved. Such a deformation mechanism was used to fabricate printed nylon (dielectric constant $\varepsilon_{\mathrm{r}}=3.1$ ) material embedded with carbon fibers.

An improved 3D printer manufactures the composite substrate. The polymer material is fed into the 3D-print head through the motor and is heated to a molten state inside the print head. Under the thrust of the continuous feeding of the polymer material, the molten 
polymer enters the nozzle. At the same time, continuous carbon fiber filaments are also fed into the 3D-printing head, where they are wrapped by molten polymer at the nozzle to form a composite material, and then extruded from the nozzle, and rapidly cooled and solidified on the printing platform, so that the carbon fiber can continue from the nozzle is pulled out. Finally, the composite substrate is formed according to the XY axis of the printer according to the set program. We have used a method similar to [14] to manufacture the composite substrate. As shown in Figure 1, the controllable deformation of the composite material was realized by designing curved fiber paths.

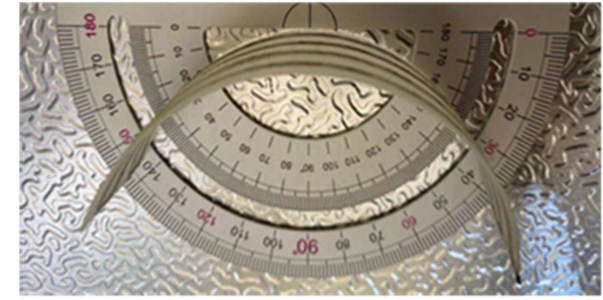

(a)

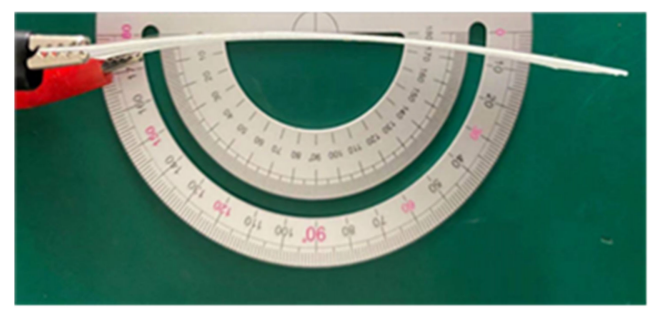

(c)

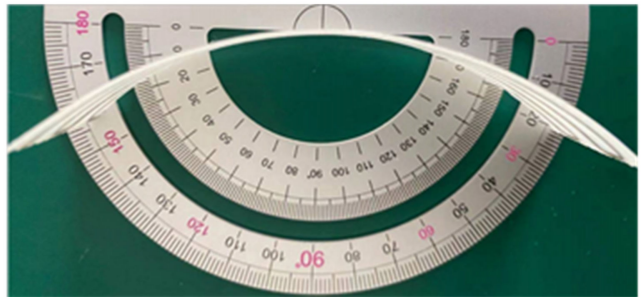

(b)

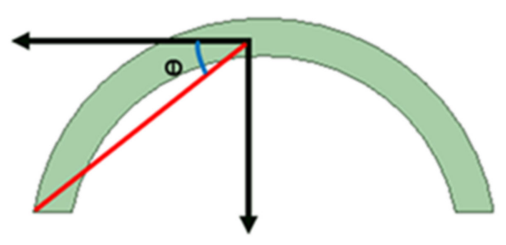

(d)

Figure 1. (a) $-20^{\circ} \mathrm{C}$, substrate bending; (b) room temperature, substrate deformation;(c) $25 \mathrm{~V}, 130 \mathrm{~mA}$, substrate stretch; (d) schematic diagram of angle measurement.

The deformation process of the substrate was measured. Figure 1a shows the bending state of the substrate at $-20^{\circ} \mathrm{C}$. Because of the significant difference in the heat deformation performance between the carbon fiber bundle and the polymer matrix, this laminate structure underwent a considerable but controllable bending behavior within $1 \mathrm{~min}$. As the temperature was gradually increased, the bending state weakened, and the substrate gradually stretched at room temperature (Figure $1 \mathrm{~b}$ ). Figure 1c shows that the substrate stretched when the carbon fiber energized. Figure $1 \mathrm{~d}$ presents a schematic diagram of the angle measurement. There is a difference in thermal expansion coefficient between carbon fiber and nylon. The carbon fiber opening was connected to a power to measure the stretching and contraction processes of the substrate under power-on and power-off conditions, respectively (Figure 2).

Figure 2a presents the deformation process of the substrate under carbon fiber energized at room temperature. Specifically, as the voltage at both ends of the carbon fiber increases, the heat released from the carbon fiber increases gradually, only requiring $45 \mathrm{~s}$ for the substrate to stretch completely at $30 \mathrm{~V}$. It shows that as the power increases, the Joule heat released by the carbon fiber causes the substrate to deform rapidly. Figure $2 b$ displays the contraction of the substrate upon power-off, where the contraction rate slowed gradually, reaching the initial bending degree at room temperature. Changes in ambient temperature will also affect structural deformation. Compared with the case of power supply at room temperature, the deformation process of the structure under the condition of $-30{ }^{\circ} \mathrm{C}$ is more severe. It is because the lower the ambient temperature, the larger the bending angle of the structure. 


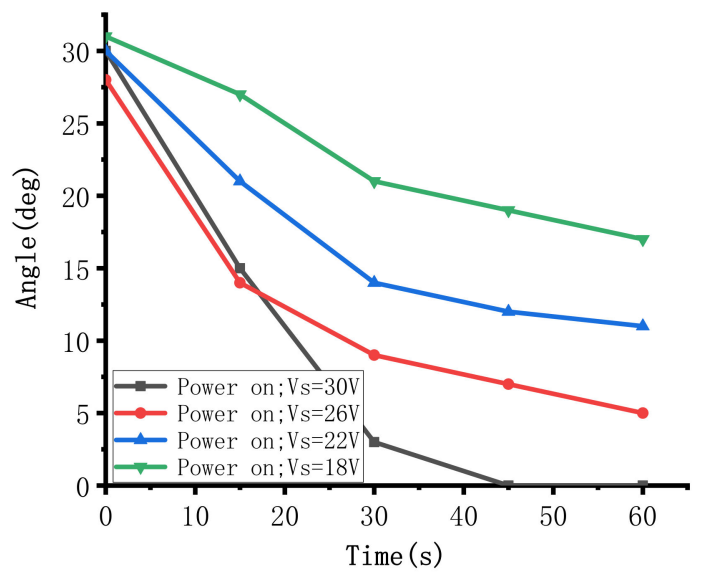

(a)

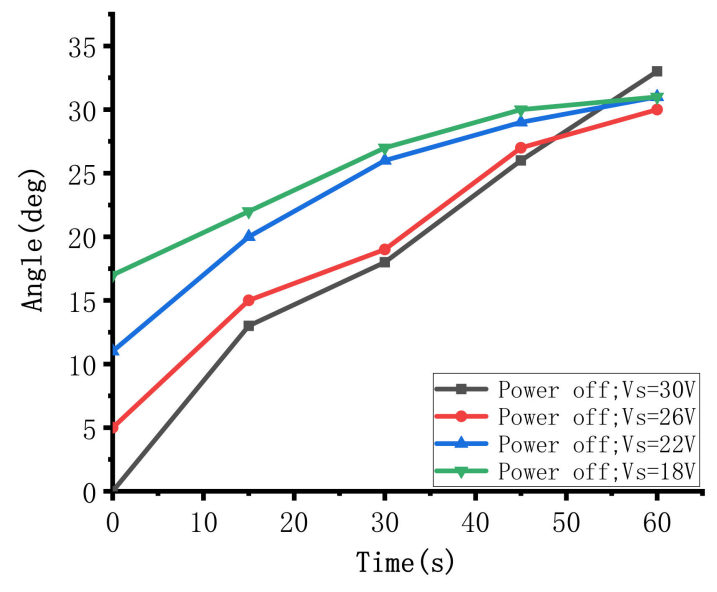

(b)

Figure 2. The angle of the measured substrate deformation at room temperature. (a) stretching angle of the substrate versus time under different power levels; and (b) automatic contraction of the substrate versus time after power-off.

The bending properties of nylon and carbon fiber materials are reproducible, i.e., the recovery and cycling properties of these materials in response to deformation are repeatable after multiple power-on/heating and power-off/cooling cycles. This is possible through the mismatch between the thermal stresses of the continuous carbon fiber and pure thermoplastic polymer [14].

\section{Design and Analysis of Bowtie Antenna}

The bowtie antenna was chosen for its design simplicity, enabling easy interpretation of the geometry changes during deformation. In addition, the bowtie antenna has the advantages of broad bandwidth, low cross-polarization, and high gain [15-18]. The design of broadband antennas should follow the principles of increasing the dependence on antenna angle $[19,20]$. The bowtie antenna in this study was designed on flexible copper clad laminate (FCCL) material (dielectric constant $\varepsilon_{\mathrm{r}}<4$ ) with a thickness of $0.1 \mathrm{~mm}$. In addition, as a flexible material, FCCL is suitable for surface mounting of an antenna, and most importantly, FCCL can withstand high temperatures.

The primary antenna geometry is shown in Figure 3. Specifically, Figure 3a is the top view of the composite substrate. The bow-tie antenna is installed on the upper surface of the composite substrate. The lower surface of the composite substrate is S-shaped, regularly arranged carbon fiber material. The diameter of the carbon fiber is $1 \mathrm{~mm}$, and the spacing between adjacent carbon fiber bands is $4.5 \mathrm{~mm}$ on the bottom surface of the composite substrate. Furthermore, Figure $3 \mathrm{~b}$ shows the geometry of the bow-tie antenna. Figure $3 \mathrm{c}$ shows the composite substrate-bending model. The specific geometry dimensions of the antenna structure are listed in Table 1.

Figure 4 illustrates the HFSS simulation results of the relationship between the maximum gain of the antenna radiation and the bending angle or frequency. The maximum gain first increases gradually with the bending angle, reaching a maximum value near $15^{\circ}$, and then decays rapidly along with further bending. When the bending angle is smaller than $15^{\circ}$, the antenna tends to behave as a V-shaped dipole with increased power density in the end-fire direction. When the angle is greater than $25^{\circ}$, the coupling effect between the two arms of the bowtie antenna is enhanced, and the far-field power density decreases. 


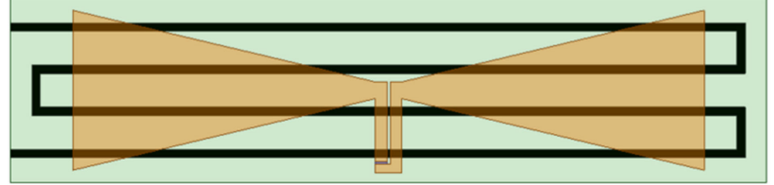

Bow-tie

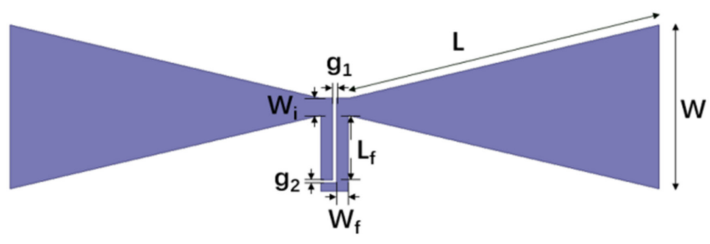

Carbon fibre

(a)

(b)

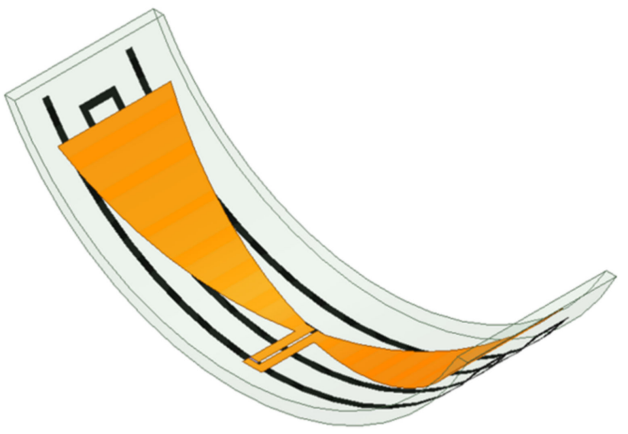

(c)

Figure 3. (a) Composite substrate and bowtie antenna; (b) bowtie antenna dimensions; (c) the size of the substrate is $90 \mathrm{~mm} \times 20 \mathrm{~mm} \times 2 \mathrm{~mm}$, and bending $30^{\circ}$.

Table 1. Dimensions of the bow-tie antenna.

\begin{tabular}{cc}
\hline Parameter & Value $^{*}$ \\
\hline $\mathrm{L}$ & 37 \\
$\mathrm{~W}$ & 19 \\
$\mathrm{~W}_{\mathrm{i}}$ & 2 \\
$\mathrm{~g}_{1}$ & 0.4 \\
$\mathrm{~g}_{2}$ & 0.3 \\
$\mathrm{~W}_{\mathrm{f}}$ & 1.4 \\
$\mathrm{~L}_{\mathrm{f}}$ & 1.8 \\
\hline
\end{tabular}

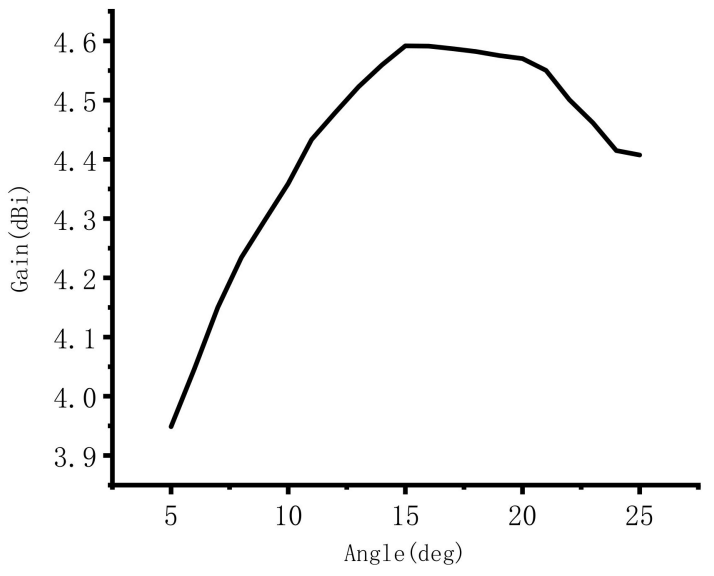

(a)

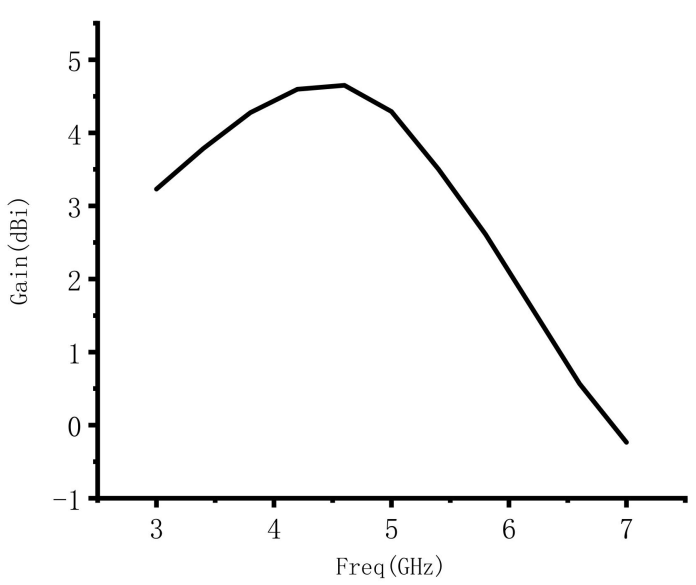

(b)

Figure 4. The simulation results of the maximum gain versus (a) bending angle (b) frequency. 


\section{Simulation and Measurement Results}

The photograph of the fabricated antenna element is shown in Figure 5. In the measurement, the reflection coefficient was measured with an Agilent E8363B PNA series Network Analyzer.

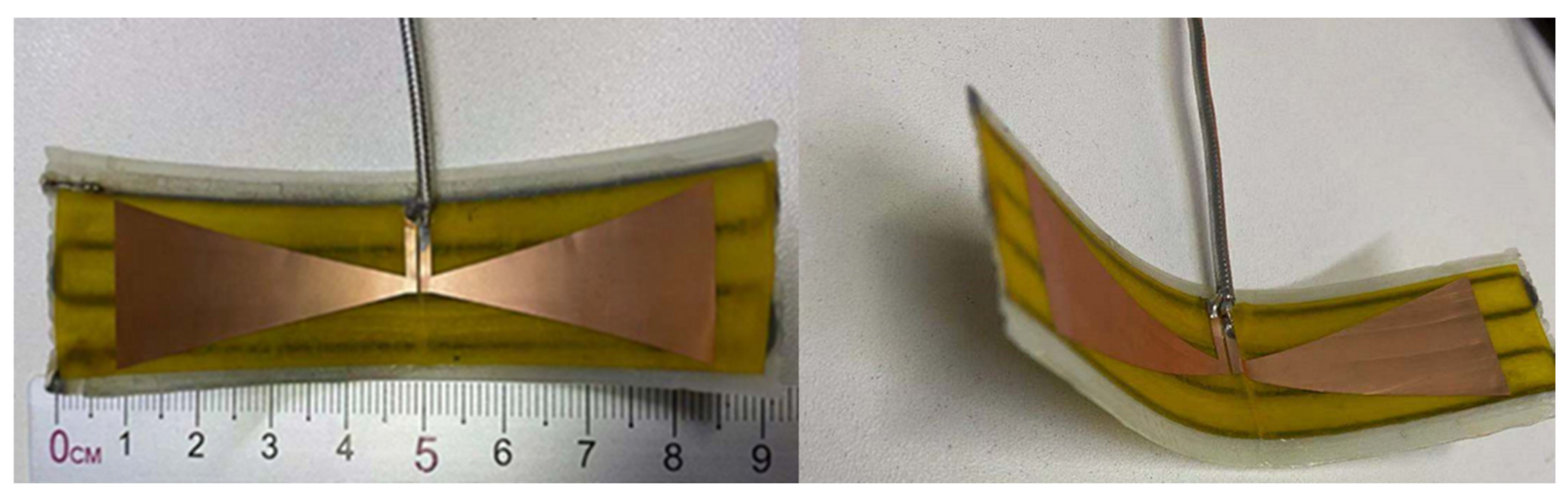

Figure 5. Photograph of the fabricated deformable bowtie antenna.

Energized carbon fiber-heating substrate, the substrate quickly stretched into flat, and the $-10 \mathrm{~dB}$ bandwidth divided into two ranges of $4.28-4.64 \mathrm{GHz}$ and $5.16-5.52 \mathrm{GHz}$ for the test results. Figure 6 presents the simulation and test results of S11, where the simulated $10 \mathrm{~dB}$ bandwidth is from $3.7 \mathrm{GHz}$ to $5.96 \mathrm{GHz}$. For the test results, the $-10 \mathrm{~dB}$ bandwidth ranged from $4.12 \mathrm{GHz}$ to $5.6 \mathrm{GHz}$ at room temperature without carbon fiber heating, and the bending angle of the substrate was $30^{\circ}$. The factor causing this difference was the change in substrate parameters after the substrate was heated.

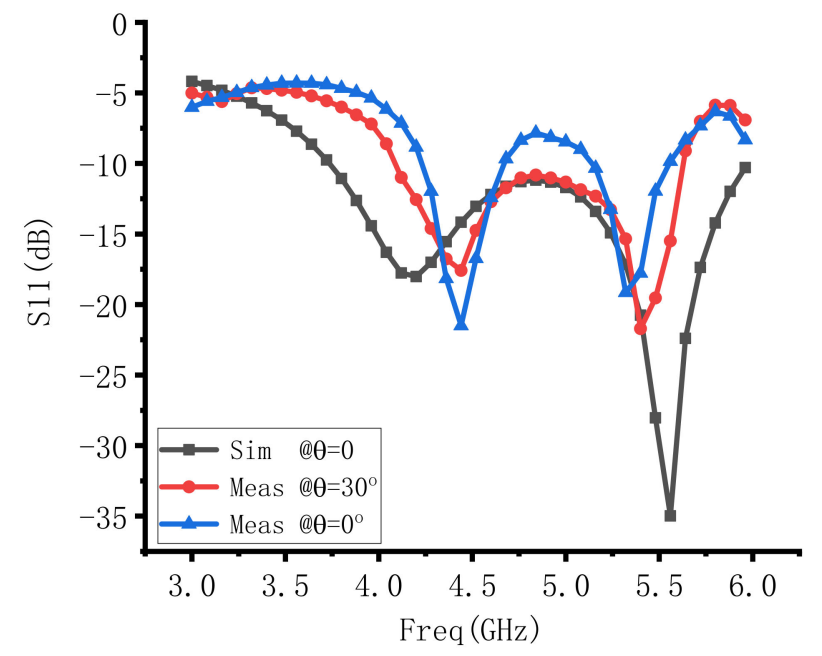

Figure 6. Simulation and measurement return loss for different bending angle $(\theta)$.

Figure 7 shows the simulation and test results under different scenarios. The radiation patterns of the antenna were observed in the $\mathrm{E}$ and $\mathrm{H}$ planes. Figure $7 \mathrm{a}$ shows the simulation radiation pattern in the $\mathrm{E}$ and $\mathrm{H}$-plane at $4.5 \mathrm{GHz}$ with a substrate heated by energized carbon fibers, while the measuring radiation pattern in the E and H-plane under identical conditions is displayed in Figure $7 \mathrm{~b}$. When the antenna was fully stretched out, the beamwidth became larger, the measured maximum gain was $2.37 \mathrm{dBi}$, and the half-power beamwidth was greater than $60^{\circ}$. Figure $7 \mathrm{c}$ presents the simulation radiation pattern in the E and H-plane at $4.5 \mathrm{GHz}$ and room temperature without heating, while the measuring radiation pattern is shown in Figure $7 \mathrm{~d}$. Owing to substrate bending, the 
far-field power density is more accumulated, with a measured maximum gain of $3.58 \mathrm{dBi}$ and an antenna half-power beamwidth close to $45^{\circ}$.

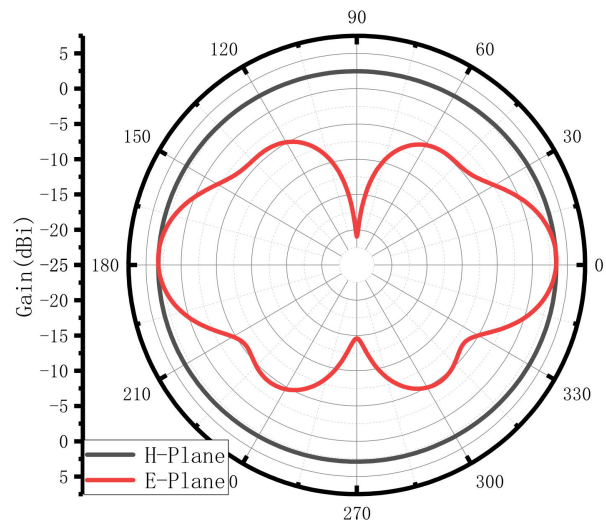

(a)

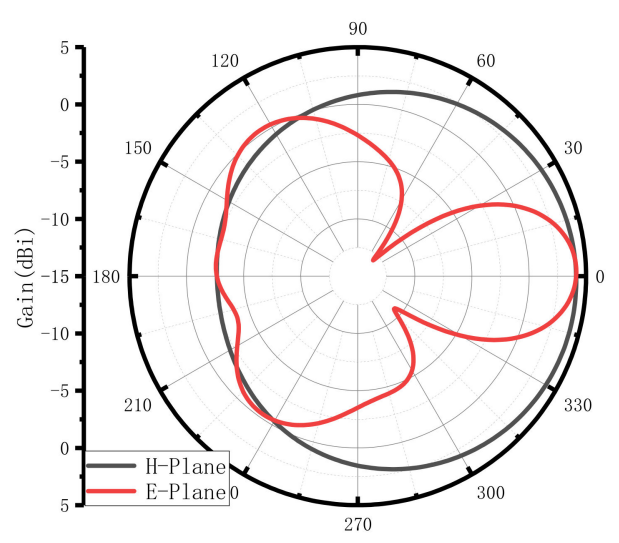

(c)

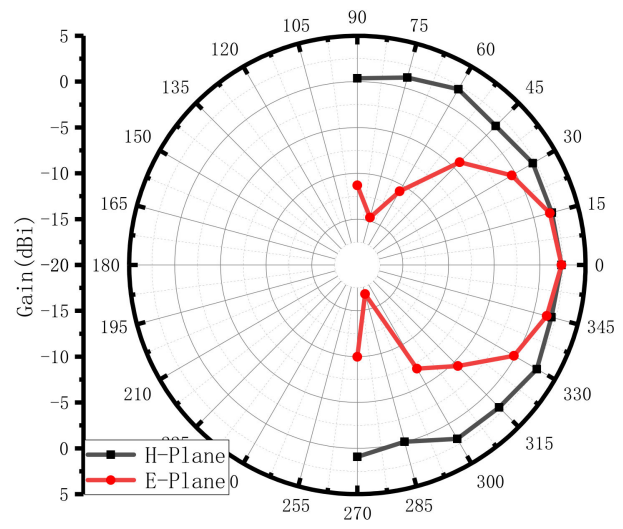

(b)

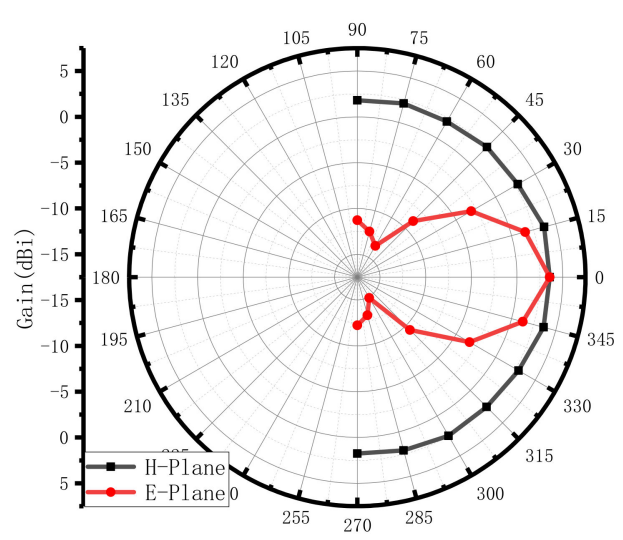

(d)

Figure 7. 4.5 GHz radiation patterns in the (a) simulation and (b) measuring with heating, and the (c) simulation and (d) measuring at room temperature without heating.

A performance comparison of the proposed work with antennas designed on the frequencies of interest is provided in Table 2. This shows that attaining high gain profiles usually restricts the bandwidth, while high bandwidth suffers gain trade-off [9]. Reconfigurable antennas need to be generated with the help of external fields or reconfiguration of the antenna length in $[6,8]$. Gain bandwidth optimization is usually performed by using auxiliary structures or increasing the area; for example, Ref. [14] reported directivity and sacrificial area planar structures. The comparison concluded that adding an antenna deformation reconstruction dimension can dynamically switch between different antenna performances, making the application of the antenna more flexible. The antenna structure is changed by external stimuli to dynamically obtain radiation characteristics, which can use $5 \mathrm{G}$ communications to adapt to complex wireless environments and be used in flexible electronics or wearable devices. 
Table 2. Comparison of proposed work with recent antennas.

\begin{tabular}{ccccc}
\hline & Bandwidth $(\mathbf{G H z})$ & Gain $(\mathbf{d B i})$ & Flex./Conf. & \\
\hline 6 & $1.91-1.99$ & & $\mathrm{Y}$ & recon. \\
\hline 8 & $25.1-26.1$ & & $\mathrm{Y}$ & recon. \\
\hline 9 & $26-40$ & 8.76 & $\mathrm{Y}$ & Single beam beams \\
\hline 11 & around 7.24 & 2.6 & $\mathrm{Y}$ & Omnidir. \\
\hline \multirow{2}{*}{ This work } & $3.28-4.46 / 5.16-5.52$ Flat & 4 & $\mathrm{~N}$ & Tunable Freq. \& Beamwidth \& Gain \\
\hline
\end{tabular}

\section{Conclusions}

In this paper, a novel electrically controllable deformable antenna was designed and fabricated using a 4D-printed substrate combined with a bowtie antenna. This structure provides a wide frequency range and radiation characteristics and can be used in 5G communications, flexible electronics, and wearable devices. The control of antenna beamwidth and gain was achieved by implementing electrically controllable deformation of the $4 \mathrm{D}$-printed substrate. Finally, the design was validated through simulation and measurement.

Author Contributions: Conceptualization, L.W. and H.C.; data curation, L.W. and H.C.; formal analysis, B.S. and H.C.; funding acquisition, B.S. and H.C.; investigation, J.H.; methodology, B.S. and H.C.; project administration, H.C., S.H. and H.L.; resources, H.C.; software, L.W. and M.Z.; supervision, H.C.; validation, L.W., J.H. and M.Z.; visualization, H.C.; writing-original draft, L.W.; writing-review and editing, S.H. and H.L. All authors have read and agreed to the published version of the manuscript.

Funding: This work was funded by the National Key Research and Development Program of China under Grant No. 2016YFA0201903 and 2016YFA0202304, Research and Development Projects in Key Fields of Guangdong Province under Grant No. 2020B010171001. as well as the Opening Project of Key Laboratory of Microelectronics Devices and Integrated Technology, Institute of Microelectronics, Chinese Academy of Sciences.

Data Availability Statement: Data is contained within the article.

Conflicts of Interest: The authors declare no conflict of interest.

\section{References}

1. Kuang, X.; Chen, K.; Dunn, C.K.; Wu, J.; Li, V.C.F.; Qi, H.J. 3D Printing of Highly Stretchable, Shape-Memory, and Self-Healing Elastomer toward Novel 4D Printing. ACS Appl. Mater. Interfaces 2018, 10, 7381-7388. [CrossRef] [PubMed]

2. Deng, D.; Chen, Y. 4D Printing: Design and Fabrication of 3D Shell Structures with Curved Surfaces Using Controlled SelfFolding. In Proceedings of the ASME 2015 International Manufacturing Science and Engineering Conference, Charlotte, NC, USA, 8-12 June 2015; pp. 154-196.

3. Ding, Z.; Yuan, C.; Peng, X.; Wang, T.; Qi, H.J.; Dunn, M.L. Direct 4D printing via active composite materials. Sci. Adv. 2017, 3, e1602890. [CrossRef] [PubMed]

4. Zhou, Y.; Huang, W.M.; Kang, S.F.; Wu, X.L.; Lu, H.B.; Fu, J.; Cui, H. From 3D to 4D printing: Approaches and typical applications. J. Mech. Sci. Technol. 2015, 29, 4281-4288. [CrossRef]

5. Leist, S.K.; Gao, D.; Chiou, R.; Zhou, J. Investigating the shape memory properties of 4D printed polylactic acid (PLA) and the concept of 4D printing onto nylon fabrics for the creation of smart textiles. Virtual Phys. Prototyp. 2017, 12, 290-300. [CrossRef]

6. So, J.-H.; Thelen, J.; Qusba, A.; Hayes, G.J.; Lazzi, G.; Dickey, M.D. Reversibly Deformable and Mechanically Tunable Fluidic Antennas. Adv. Funct. Mater. 2009, 19, 3632-3637. [CrossRef]

7. Dejean, G.; Bairavasubramanian, R.; Thompson, D.; Ponchak, G.; Tentzeris, M.; Papapolymerou, J. Liquid crystal polymer (LCP): A new organic material for the development of multilayer dual-frequency/dual-polarization flexible antenna arrays. IEEE Antennas Wirel. Propag. Lett. 2005, 4, 22-26. [CrossRef]

8. Langer, J.-C.; Zou, J.; Liu, C.; Bernhard, J. Micromachined reconfigurable out-of-plane microstrip patch antenna using plastic deformation magnetic actuation. IEEE Microw. Wirel. Compon. Lett. 2003, 13, 120-122. [CrossRef] 
9. Jilani, S.F.; Munoz, M.O.; Abbasi, Q.H.; Alomainy, A. Millimeter-Wave Liquid Crystal Polymer Based Conformal Antenna Array for 5G Applications. IEEE Antennas Wirel. Propag. Lett. 2019, 18, 84-88. [CrossRef]

10. Jilani, S.F.; Falade, O.P.; Wildsmith, T.; Reip, P.; Alomainy, A. A 60-GHz Ultra-Thin and Flexible Metasurface for FrequencySelective Wireless Applications. Appl. Sci. 2019, 9, 945. [CrossRef]

11. Rahimian, A.; Alfadhl, Y.; Alomainy, A. Analytical and numerical evaluations of flexible V-band rotman lens beamforming network performance for conformal wireless subsystems. Prog. Electromagn. Res. B 2016, 71, 77-89. [CrossRef]

12. Jilani, S.F.; Rahimian, A.; Alfadhl, Y.; Alomainy, A. Low-profile flexible frequency-reconfigurable millimetre-wave antenna for 5G applications. Flex. Print. Electron. 2018, 3, 035003. [CrossRef]

13. Baek, C.-W.; Song, S.; Park, J.-H.; Lee, S.; Kim, J.-M.; Choi, W.; Cheon, C.; Kim, Y.-K.; Kwon, Y. A V-band micromachined 2-D beam-steering antenna driven by magnetic force with polymer-based hinges. IEEE Trans. Microw. Theory Tech. 2003, 51, 325-331. [CrossRef]

14. Yang, C.; Wang, B.; Li, D.; Tian, X. Modelling and characterisation for the responsive performance of CF/PLA and CF/PEEK smart materials fabricated by 4D printing. Virtual Phys. Prototyp. 2017, 12, 69-76. [CrossRef]

15. Durgun, A.; Balanis, C.A.; Birtcher, C.R.; Allee, D.R. Radiation characteristics of a flexible bow-tie antenna. In Proceedings of the 2011 IEEE International Symposium on Antennas and Propagation (APSURSI), Spokane, WA, USA, 3-8 July 2011; pp. 1239-1242.

16. Zheng, G.; Kishk, A.A.; Glisson, A.W.; Yakovlev, A.B. A broadband printed bow-tie antenna with a simplified balanced feed. Microw. Opt. Technol. Lett. 2005, 47, 534-536. [CrossRef]

17. Lin, Y.-D.; Tsai, S.-N. Coplanar waveguide-fed uniplanar bow-tie antenna. IEEE Trans. Antennas Propag. 1997, 45, 305-306. [CrossRef]

18. George, J.; Deepukumar, M.; Aanandan, C.; Mohanan, P.; Nair, K. New compact microstrip antenna. Electron. Lett. 1996, $32,508$. [CrossRef]

19. Eldek, A.A.; Elsherbeni, A.Z.; Smith, C.E. Wideband 2D array of microstrip fed rectangular-slot antennas for radar applications. Microw. Opt. Technol. Lett. 2005, 46, 36-40. [CrossRef]

20. Karacolak, T.; Topsakal, E. A Double-Sided Rounded Bow-Tie Antenna (DSRBA) for UWB Communication. IEEE Antennas Wirel. Propag. Lett. 2006, 5, 446-449. [CrossRef] 